Fecha de recepción: diciembre 2018 Fecha de aceptación: marzo 2019 Versión final: junio 2019

\section{El camino de la heroína, el arquetipo femenino universal para un nuevo paradigma.} Gabriel Los Santos * y Tomás Stiegwardt **

Resumen: En el territorio de la narrativa, los relatos se han establecido a partir de una concepción patriarcal desde los tiempos fundacionales de la cultura. Sin embargo, las heroínas han existido desde Aristófanes (Lisistrata: La rebelión de las mujeres): personajes como Juana de Arco, la reina celta Boudicca, Juana Azurduy hasta Mérida de Valiente de PIxar, Katniss Everdeen en Los Juegos del Hambre, Khalessi o Arya de Juego de Tronos, Capitana Marvel o Mujer Maravilla, Beatrix Kiddo de Kill Bill, Trinity en Matrix, Rey la chatarrera de Star Wars que encarna "La Fuerza" y enfrenta al imperio. Así, existen cientos de ejemplos donde se observa un cambio estructural, estético y ético que aporta una nueva mirada a la narrativa.

En los últimos tiempos se observa un importante avance de la mujer en distintos ámbitos sociales gracias a la potencia individual de algunas pensadoras de avanzada y a las luchas de los movimientos feministas. Como consecuencia del trabajo permanente de las mujeres y en línea directa con el fracaso del modelo patriarcal, puede verse un resquebrajamiento en las estructuras sociales, cuya epidermis ha sido cuarteada por los acontecimientos históricos. Es decir que el proceso de transformación social hacia la equidad de género atraviesa la estructura misma de nuestra sociedad, y se hace patente en los diferentes aspectos de la cultura en su definición más amplia.

La aparición de un nuevo tipo de personaje femenino -hasta ahora vedado como modelopone en jaque las estructuras sociales arquetípicas existentes y se erige como una promesa de cambio para una nueva narrativa más amplia, inclusiva y diversa.

Hoy día puede observarse una creciente participación de mujeres empoderadas en todos los estratos de la sociedad. Esto sucede tanto en el ámbito del mundo real como en su espejo cultural a través de las más diversas producciones del cine, la televisión, la literatura, los medios de comunicación y las plataformas digitales. Esta suerte de democratización de la información y de los criterios estéticos y argumentales inaugura de forma lenta pero segura una nueva manera de interpretar al mundo. Uno de sus aspectos más activos, reconocibles y presentes puede observarse en el relato audiovisual, en donde la aparición de nuevos modelos de mujeres heroicas, con valores intrínsecamente ligados a lo femenino e igualitario, arrasan, no sólo en el discurso sino también en las plateas y en las elecciones del público.

Si para la humanidad el narrar historias ha sido fundante de sus propias culturas, el cambio de signo en la manera y forma en que se mira y por ende relata cambia el sentido de la historia, brindando una nueva cosmovisión. El nuevo relato ya no será igual al anterior ni su opuesto: será una concepción totalmente diferente, transversal, multidimensional, integradora y creativa. 
Palabras clave: Heroína - mujer - género - narrativa - arquetipo - paradigma - empoderamiento - femenino - mapa - territorio.

[Resúmenes en inglés y portugués en las páginas 43-45]

${ }^{(*)}$ Académico, dramaturgo y cineasta. Licenciado en Enseñanza de las Artes Audiovisuales (UNSAM) y Puesta en Escena (EMAD). Estrena obras de teatro en España y Argentina. Gana Proteatro, Fondo Nacional de las Artes. Creador del Método de Actuación "Movilidad Energética", organiza el Encuentro Internacional de entrenamiento actoral auspiciado por el Ayuntamiento de Aragón (España). Obtiene premios en Cuba y Argentina. Expone material audiovisual en la University of Illinois at Urbana-Champaign (USA) Enseña cine y pedagogía del diseño. En la Universidad de Palermo Gabriel es Director del Área Audiovisual de la Facultad de Diseño y Comunicación.

${ }^{(*)}$ Ilustrador, cineasta, guionista y académico. Licenciado en Diseño (UP), Profesor egresado de la Escuela Nacional de Bellas Artes y Realizador de Cine y TV de la Escuela Superior de Cinematografía. Gana las becas Subiela, Ibermedia y UP. Obtiene numerosos premios de guion y dirección y gana el Fondo Nacional de las Artes 2018. Su proyecto Diablillos Estelares es premiado en Expotoons y por el Gobierno de la Ciudad y es invitado por Dreamworks. Diserta sobre cine y creatividad en la University of Illinois at UrbanaChampaign (USA). Escribe papers sobre creatividad y arte. Tomas enseña realización de cine, guión y producción en la Universidad de Palermo.

EOWIN: - Haz lo que quieras, más yo lo impediré si está en mis manos ESPECTRO: - Impedírmelo! ¿A mí? Estás loco. ¡Ningún hombre viviente puede impedirme nada!

EOWIN: -jEs que no soy ningún hombre viviente! Lo que tus ojos ven es una mujer. (...)

(Tolkien J.R.R - 1954 - El señor de los anillos)

En la narrativa mundial, sea ésta en el universo literario, teatral y en el audiovisual, se han creado construcciones tanto en el nivel de la estructura dramática como en la conformación tipológica y arquetípica de personajes.

En la Grecia antigua nace y se desarrolla una manera de entender la forma de contar cuentos, historias y obras de representación que han desarrollado una visión y un crecimiento arquetípico de personajes, cuyos héroes son, en esencia, masculinos. Desde el punto de vista centrado en la tradición narrativa de Occidente y el lugar que han ocupado las mujeres en su épica y desarrollo de la tradición narrativa, el salto cuántico dado en estos últimos y muy recientes tiempos, es asombroso. 
Sin embargo, la pulsión y la energía para este cambio siempre estuvo allí, en el humus de la historia, listo para surgir y ahora, en este tiempo histórico lo hace con toda su potencia y diversidad. Salvaje y contundente. Vital y renovadora, esta energía se introduce con fuerza y poder en esta nueva etapa en la sociedad y se refleja en los medios, la realización cinematográfica, y en la narrativa de los cómics, las novelas, el cine y muy notoriamente en las series que se producen para Netflix, Amazon, HBO y otras. Los cambios suscitados por la sociedad, los medios y, en definitiva, la cultura, han echado raíces en donde la memoria se contiene y propaga: en las historias. Como consecuencia de esta nueva interacción entre el mundo y la humanidad, el universo narrativo y audiovisual está recibiendo toda la influencia de este cambio, produciéndose así una verdadera operación de transposición de los núcleos del pensamiento -y su sustrato emocional- que ya afecta en la actualidad y transformará para siempre la forma en que vemos y entendemos.

Mutan las historias puesto que nuevos personajes femeninos han salido a la luz desde las miradas más diversas y se suman con su potencia disruptiva a una nueva dinámica comunicacional y narrativa. Impensadas formas arquetípicas se están desarrollando en todos los ámbitos y en los lugares más distintos y diversos, y evolucionarán hacia formas inesperadas para la mentalidad presente y hacen brotar desde el fondo del inconsciente colectivo, de los espacios negados de la historia y la pulsión imparable del advenimiento de la mujer a su justo y necesario lugar en el mundo.

A la vanguardia de la cultura pop, las revistas de historietas han sido pioneras en la construcción de súper heroínas pudiéndose nombrar a miles de personajes entre ellas a Rogue, Phoenix o Storm de los X-Men, Barbarella, Xena, Batichica, Electra, La Viuda Negra. Raven o She Ra, Aeon Flux, Sailor Moon o Bárbara y miles otras. Sin embargo, sus caminos han sido lentos en su ascensión al monte del éxito audiovisual.

Los héroes de la ficción literaria, de las leyendas y del teatro, junto con una buena parte de la historia del cine, han sido y aún son, en su mayoría, masculinos. Desde Hércules a Perseo y de Aquiles a Héctor en el mundo griego, Rodrigo Díaz de Vivar o Rolando para la cultura hispánica, Arturo Pendragon en el Avalon místico de la leyenda de Excalibur, los poderosos Thor o Loki de las sagas nórdicas reelaboradas como superhéroes por el cómic y el cine por la Compañía Marvel y su panteón iconográfico de personajes como Capitán América, Iron Man y Hulk entre otros miles de productos creativos culturales han sido los moldes en los cuales se ha volcado la construcción de heroicidad, y por lo tanto ideal simbólico de esta era. Mientras que Superman, Batman o Flash por parte de la Empresa DC Comics continúan conjurando los fantasmas arquetípicos del héroe masculino. No solo en las dos grandes incubadoras de superhéroes (Marvel y DC Comics) sino en muchas otras fuentes narrativas, se han creado una variedad de personajes que llenan las pantallas y revistas, libros y dispositivos con cantidad de versiones heroicas con diversos poderes, debilidades, actitudes e intereses. En la ciencia ficción se han consagrado en la historia del cine personajes heroicos como Luke Skywalker de La Guerra de las Galaxias, Capitán Kirk de Star Trek, Harry Potter o el aún más antiguo Flash Gordon. Los héroes "duros" del cine de aventuras moderno de Hollywood como Rambo, John Wick o Harry el sucio y tantísimos otros. Héroes reconstituidos desde fragmentos de la historia como el William Wallace de Corazón Valiente o Máximo Meridio de Gladiador. En el mundo del animé tradicional de los años setenta aparecen Meteoro, Astroboy, Mazzinger, los Caballeros del 
Zodíaco, Goku, etc. En las historietas tenemos a Nippur de Lagash, Den, Paturuzú, Asterix y Obelix, Dick Tracy o Lucky Luck.

Nota: En los ámbitos del animé y el manga la aparición temprana de heroínas femeninas es notable: Sailor Moon, Ghost in the Shell y aún la producción de Heidi muestran la fuerza potencial y manifiesta de lo femenino de diversas maneras.

El humor gráfico y las viñetas realizadas para diarios y revistas han dado lugar en la Argentina y el mundodesde las décadas del sesenta a otro tipo de personaje nacido de la observación sagazy la expresión certera: La heroína intelectual. Quizás uno de los ejemplos más contundentes de esta categoría es Mafalda el personaje creado por Quino (Joaquín Lavado). A lo largo de cientos de tiras entre los años 1964 y 1973, Mafalda se ha convertido en un ícono, en sinónimo de valentía intelectual, ocurrencia contundente y voluntad inquebrantable para la expresión libre de un pensamiento y una mirada crítica de la realidad.

Otra forma de heroicidad mucho menos reconocida como tal, pero de un renovador potencial de sanación es la que expresan los personajes femeninos creados por la ilustradora argentina Maitena (Inés Burundarena Streb). Sus mujeres -lejos de la idealización y de cualquier intento de fingida perfección- son los suficientemente valientes para expresar sus miedos, sus angustias y aún sus contradicciones. La aceptación, la confesión, el reconocimiento de errores y problemas, y en definitiva, el mostrarse como mujeres reales, es en este mundo un acto sin duda heroico.

Esta tipología de personajes son un aporte sustancial para la formulación o encuentro de un nuevo arquetipo en donde el ideal no queda sometido a la inexistencia utópica o fantasiosa(ni mucho menos a las expectativas sociales prejuiciadas) sino que se ancla en el espacio mucho más complejo, profundo, completo y dinámico de la incertidumbre, de donde sin duda emergerán formas mucho menos previsibles pero inmensamente vitales y transformadoras, que darán forma a nuevos mundos, otros personajes e innovadoras historias.

En el año 1949 Joseph Campbell publica su libro El Héroe de las mil caras de donde surge una conceptualización desarrollada en cuanto a los pasos y procesos por los que debe pasar un héroe. Estos textos, junto a aportaciones de Vogler y otros se han constituido en lineamientos -cuando no en manuales- para la estructuración de personajes para un guion de la industria del cine.

En este esquema, se los ha divido en estadios por lo que el héroe debe pasar, pruebas que debe soportar, enigmas para dilucidar, monstruos a derrotar y pasiones que sublimar. Estas ideas se han resumido como El Camino del Héroe y son de estudio obligatorio en casi cualquier curso o carrera de guion. Así se han logrado sistematizar los procesos para una inmensa cantidad de aspirantes a protagonistas heroicos, muchos con resultados fantásticos y otros lamentables. El camino del héroe suele tener unos 12 pasos (algunos lo ven en 16 o más) pero en todo caso su forma simula un reloj dividido en etapas con pruebas a ser atravesadas. Esta secuenciación es lineal y consecutiva. No hay lugar para saltos, atajos ni vuelta atrás. Tampoco para intercambio de cuadrantes ni alteraciones. De esta forma se confirma que el Camino del héroe es esencialmente una sistematización de una forma de pensamiento masculino. De hecho, la sola idea de armar un recetario que calce para todas las circunstancias y momento es una función que ejecuta el lado izquierdo del cerebro con sus características de pensamiento racional, sucesivo, matemático, lógico y concreto. El lado derecho, con sus funciones creativas, holográficas, simultáneas, sensoriales, intuitivas 
y multidimensionales, no puede $-\mathrm{y}$ no quiere- responder a este paradigma. Es, en esencia y forma, el lado femenino del cerebro y como tal opera en la persona. En este sentido, podríamos decir que las formas racionales del pensamiento (incluso en sus funciones creativas) tienen un predominio de mentalidad newtoniana mientras que aquellas vinculadas con lo creativo y femenino son holísticas y cuánticas. En la correspondencia entre esto y el universo de la narrativa se puede observar que la necesidad de formalizar sistemas es esencialmente masculina. Aquí es importante mencionar que "masculino" no se refiere necesariamente a un varón físico sino a un sistema que en este momento es dominante. Una forma de ver el mundo que en los aspectos sociales y de género se ha dado en llamar el patriarcado. Algunos movimientos proponen frente a esto y como contraparte, un "matriarcado" y en estos tiempos altamente polarizados no es extraño que resulten seductoras las propuestas que se opongan a lo que se aborrece. Sin embargo y a efectos de este trabajo se propone un modelo superador. Por encima de manifiestos que se revelan estancos y de prejuicios insalvables. El gran desafío que presenta la construcción de un modelo narrativo para un camino de la heroína queda entonces impregnado por más preguntas que respuestas.

¿Cómo establecer lineamientos para la construcción de un sistema de pensamiento que incluya la variable emocional, instintiva e intuitiva en una forma orgánica y comprensible? Por ello, la sola idea de una heroína es revolucionaria. Es verdad que el sistema usufructuará de cualquier intento de libertad del pensamiento y aún de un movimiento feminista a ultranza, de hecho, el estreno mundial de Capitana Marvel como máxima potencia del universo Marvel no puede considerarse solo un avance en este sentido (aunque lo es) pero también una oportunidad comercial de ampliar el mercado audiovisual de los superhéroes por parte de las productoras. Lo cierto es que el estudio y la comprensión de un pasaje ritual dilucidado por Campbell de las sagas mitológicas, los cuentos y leyendas han permitido elaborar un modelo conceptual pero también ha tenido un sesgo ideológico y social. En éste, el héroe es, casi siempre, un varón. Incluso, cuando se ha buscado que calce en una heroína, se ha intentado utilizar los mismos parámetros en la suposición simplista de que el modelo era neutro. Nada más lejos. Es notorio -aunque no extraño- que se haya pasado por alto que el solo armado de un Camino del Héroe se constituye y construye sobre los valores mandantes de miles de años de cultura: el masculino, que tiene sus raíces en un sistema patriarcal, piramidal y rígido, basado en el uso del poder, la autoridad y la sanción. Desde el lugar de la construcción de historias y sus personajes nos encontramos ante un vacío histórico que ha negado la presencia en primer plano de la mujer.

Si consideramos el patriarcado como la célula elemental de toda violencia expropiadora y un tipo de estructura de tiempo larguísimo que prácticamente coincide con el tiempo de la especie, parece una estructura casi natural. Eso no evita que pensemos que es una estructura que ha sufrido modificaciones a lo largo del tiempo, que es histórica. (Segato, R (2016) La Guerra contra las mujeres, pag. 164)

No se trata solo de una cuestión formal. Se podrá argumentar también y con razón que habrá mucha más tela para cortar, más inclusiones que hacer y que la amplitud de posibilidades en virtud de los temas de género, requerirán una visión aún más global. Por ahora, 
y en vistas de una primera aproximación al tema se buscará comprender y dar forma a las características y posibilidades de un posible camino heroico para los personajes femeninos, independientemente de sus preferencias sexuales, origen étnico, creencias vitales o religiosas o realidades socio - culturales. En lo concreto del mundo audiovisual, y en especial de las transmisiones de mass media, el cambio vertiginoso se ha dado en el mundo real y en el de las pantallas. El colectivo de mujeres se ha visto empoderado por las acciones de muchas de ellas y por la unidad (sororidad) con que se han enfilado tras un discurso sólido y poderoso. En el centro del poder de Hollywood, las estrellas del cine, directoras y productoras han hecho valer su lugar en el universo audiovisual sosteniendo un discurso, que, con algunas variantes y aún con naturales contradicciones, ha hecho temblar al sistema. Desde las acusaciones de violencia, abuso y hasta violaciones por parte de productores, actores y directores han hecho caer figuras endiosadas del ámbito de la cultura, alterando programaciones y estructuras enteras de trabajo y éxitos hasta la aparición de las mujeres en roles de poder sosteniendo el mismo sistema que las mantenía en un segundo nivel de poder. El techo de cristal se ha roto o al menos ha sido mellado. El sistema, monitoreado por este colectivo está trasvasando un mundo colapsado, paternalista, piramidal, abusivo $\mathrm{y}$ dominado por la fuerza del dinero y el poder a una nueva forma cuyo sentido final aún no está definido. Quizás nunca lo esté. Y esto, es quizás su parte más maravillosa. En la naturaleza el cambio y la evolución parece ser la constante y el aspecto femenino del manejo del poder está en un proceso de crecimiento cuyo final es difícil de vislumbrar; una transformación permanente, un flujo inagotable de energías intercambiables. Las conexiones que de ello devienen ya no lineales o de mayor a menor sino desde una multiplicidad de contactos simultáneos, heterodoxos y diversos.

Lo cierto es que en la medida que esta tendencia continúe -y sin duda lo hará- la necesidad de reformular los parámetros de una narrativa que se ha anclado en arquetipos masculinos se vuelve por demás necesaria. Esto no es, como podría pensarse simplemente la suplantación de un personaje masculino por uno femenino, sino que en profundidad encontrar la voz que explicite y enmarque el advenimiento de esta nueva clase de personaje: la heroína post moderna o en definitiva, una heroína para el siglo XXI: una heroína contemporánea. La aparición en estos últimos tiempos de heroínas femeninas fuertes es, en esta ventana histórica, una fuente inagotable de posibilidades. Cabe entonces la pregunta:

\section{¿Y cómo será El Camino de la Heroína?}

Es históricamente comprobable que ha habido una gran cantidad de roles históricos y mitológicos de mujeres de diferentes temperamentos, actitudes, gustos, preferencias e ideas que han calado hondo en el proceso cultural de Occidente. En la cultura por supuesto esto ha sido mediatizado y contenido en sistemas de creencias más amplios y salvo en cortos períodos de la historia han sido monopolizados por los grandes rectores y censores del pensamiento como instituciones religiosas, de concentración del poder e incluso académicas. Es imposible pasar por alto que el rol de la mujer y su participación de la sociedad ha sido dictado por lo que el feminismo llama con razón "el patriarcado". Esto remite a una forma de pensamiento, acción y permisos que indudablemente seccionaron y coartaron la libertad de expresión y la presencia de la mujer a lo largo de siglos y aún milenios. 
Aquellas que han roto la barrera cultural han sido llamadas locas y hasta quemadas por brujas. La nueva heroína no será nada parecido a lo que se ha conocido hasta ahora. Su lugar y función en la vida real y en la narrativa, deben aún de ser descubierta y conceptualizada, y que al momento se resuelva en una forma inesperada e incluso caótica. No se pretende armar un simple esquema. De hecho, esta potencia se está conociendo a sí misma y cambiando el mundo y todo aquello que gravite alrededor de ella y su energía, será una explosión por fuera de los ámbitos conocidos y aceptados en el mundo masculino. La idea de integrar en un campo de conocimiento lineal y secuencial una serie de eventos para convertirlos en guía y fórmula es, esencialmente, una idea del varón, una forma de establecer síntesis con límites precisos, donde las fronteras sean fijas, como en la aritmética básica o las formas euclidianas, los moldes rígidos.

Las formas en las que se entablan las relaciones de poder, la forma dominante es la mirada patriarcal y masculina montada sobre una mirada sesgada por la búsqueda de dicho poder. Es por ello que el pensamiento ha sido infiltrado, guiado y estructurado desde miradas de oposición. Porque en ese mundo hay quien manda y quien obedece, amo y esclavo, dominador y sometido.

En el mundo de la modernidad no hay dualidad, hay binarismo. Mientras en la dualidad la relación es de complementariedad, la relación binaria es suplementar, un término suplementa - y no complementa - el otro. Cuando uno de esos términos se torna "universal», es decir, de representatividad general, lo que era jerarquía se transforma en abismo, y el segundo término se vuelve resto: ésta es la estructura binaria, diferente de la dual. (Segato, R (2016) La guerra contra las mujeres, pag. 118)

Más bien es de suponer que ocurrirá lo contrario. Las relaciones pueden darse transversales, dobles, imbricadas, multidimensionales y blandas; yuxtapuestas y superpuestas, delineadas o en sombras, diluidas o intensas, como forma o como tono, bajo el imperio de una directriz certera o sobre un inmenso océano de dudas. Todo esto es en este sentido, una unidad, un acto de unificación, un territorio que supera al mapa y un mapeado holográfico y transustancial.

Por lo tanto, la búsqueda de una narrativa para la heroína será una compleja superposición de capas en las que lo emocional, intelectual e instintivo que no mostrará sus bordes, sino que, al contrario, acepte de buen grado los colapsos interiores. Es dable pensar que en la medida que se profundice en esta temática habrá una inmensa serie de idas y venidas, intentos de formulaciones y hasta rígidas estructuras convertidas en estereotipos. Pero aquello posiblemente no funcionará o al menos será parcial. El mismo sentido profundo de lo femenino, con todas sus complejidades, variaciones, ambivalencias y potencialidades lo descartará progresivamente. Mientras tanto el universo audiovisual requerirá de guiones, cuentos, historias, obras de teatro, series y contenidos para este nuevo segmento. Por ello es que es preciso reflexionar sobre la búsqueda (constante, progresiva y no definitiva) de esto que hemos dado en llamar El camino de la heroína. Tiene que quedar claro -en este mundo de grietas, rechazos, peleas y polarizaciones- que nos referimos a un sentido amplio, inclusivo y diverso para el planteo de esta suerte de hipótesis primaria respecto a 
la narrativa. Para la formulación de un sistema o idea para una heroína, da lo mismo su preferencia sexual, sus gustos alimenticios o condición física. De hecho, no proponemos ningún prototipo ni biotipo sino un encuentro con una posibilidad arquetípica que englobe de forma amplia el inmenso mundo de lo femenino con sus infinitos matices.

Será sin dudas interesante observar diferentes modelos colisionando a lo largo del proceso. Por ejemplo ¿Qué sucede con la heroína madre? ¿Y una heroína abuela? ¿Cómo se complementarán los diversos roles biológicos, sociales, personales y espirituales junto con las funciones de la narrativa como lidiar con enemigos, liderar, o salvar al mundo o luchar con un monstruo gigante o contener la invasión alienígena? Habrá heroínas del Sur, del Norte y de Oriente. La heroína creyente, la laica, la compasiva y la salvaje, la heroína que sigue un modelo y la que rompe todos los moldes. La que construye con paciencia de Penélope, la que guía con sabiduría como Ariadna o la que viene a destruirlo todo cual Kali vengativa. La milennial irreverente, la soñadora de ideales luminosos y la de alma tenebrosa. Habrá heroínas con consciencia cósmica, cristianas y budistas, judías o musulmanas, heroínas tribales o chamánicas. Heroínas callejeras, sociales, rebeldes y antisistema o pacíficas, tolerantes y conciliadoras. Heroínas familiares y solitarias. Heroínas de pensamiento líquido y otras de rígidas creencias. Heroínas ciegas al mundo y otras comprensivas. Heroínas wichis, aymará, esquimales, mapuches, negras, blancas, amarillas o rojas; guaraníes, árabes, asiáticas o eslavas. Frágiles o indestructibles, nómades o asentadas. Heroínas nacidas en alguna forma de esclavitud buscando la libertad para ellas y su mundo. Heroínas millonarias o pobres, heroínas certeras y decididas y otras confusas y atribuladas. Heroínas sectarias o universalistas que compongan el alma femenina colectiva y que cambien para siempre el sentido último de su propia existencia y la de aquellos a los que su fuerza o servicio impactará con poder. Heroínas que rompen el modelo, no por oposición sino por crecimiento. Heroínas que correrán como aguas vitales desbordando diques culturales.

La construcción de un camino heroico femenino, será necesariamente revolucionario y evolutivo. Los paradigmas que han guiado la narrativa (desde la Poética aristotélica en adelante) se anclaron sin dudarlo en los mismos parámetros con lo que la sociedad enjauló y anuló a la mujer. Así como en la vida, lo espejó pues, el arte. La máscara de los personajes femeninos fue encontrando diversos espacios, pero dentro de los límites impuestos. Cuando por algún motivo esto no sucedía y emergía alguna mujer indomable, revolucionaria o demasiado audaz como Juana de Arco o la celta Boudicca, los censores formales (religiones, sistema social, etc.) accionaban las palancas de la recomposición de los valores sustentados. En la narrativa fue -entre otras- la incorporación al esquema narrativo de la figura de la bruja y la seductora. Muy diferente entonces resulta una figura como Juana de Arco a la Eva que da la manzana a Adán y con ello hace que los expulsen del paraíso. Este concepto en que pecado y castigo refieren a la mujer, ha sustentado la idea patriarcal de sujetar a la mujer a su dominio y moralizarla a través de la sumisión.

Visto a través de ese prisma, el Estado muestra su ADN masculino, pues resulta de la transformación de un espacio particular de los hombres y su tarea específica - la política en el ámbito comunitario, intercomunitario y, más tarde, ante el frente colonial y el Estado nacional- en una esfera englobante de toda 
la realidad y secuestradora de todo lo que se pretende dotado de politicidad. La genealogía de esa esfera englobante «universal y pública» proviene de aquel espacio particular de los hombres transformado a través del proceso de instalación y expansión de la colonial-modernidad. La matriz dual y reglada por la reciprocidad muta en la matriz binaria moderna, en la cual toda alteridad es una función del Uno y todo Otro tendrá que ser digerido a través de la grilla de un referente universal. (Segato, R. (2016) La guerra contra las mujeres).

Es por ello que la construcción de un camino de la heroína barre con pautas culturales muy antiguas. Al hombre no solo se le permitió ser héroe, sino que le fue exigido como parte de su credibilidad en cuanto ser existente y a su pertenencia de pleno derecho en un clan. A la mujer se la sojuzgó para que no solo no lo intentara, sino que lo rechazara tanto para ella como para el intento de otras mujeres. Las mujeres que histórica o míticamente han tomado un lugar de liderazgo, combatividad y ruptura han sido acusadas tanto por hombres como por mujeres, de no ser femeninas, constituyéndose esto en uno de los mayores insultos del tejido social de Occidente. En una demostración del poder simbólico de la palabra, el concepto de no femenino aplicado a una mujer es equivalente a no ser. Incluso en la más terrible sociedad prejuiciada, un hombre no masculino no constituye tanto un insulto como una indulgencia, una prueba de incompletitud mientras que en la mujer es la negación de su mera existencia.

La paradoja terrible es que la mujer no puede salir indemne: o es acusada como pecadora por toda la eternidad como Eva o como a Juana de Arco, se la quema en la hoguera. No resulta pues extraño que la narrativa no haya podido tomar muchos ejemplos y haya tenido que anidar para ello en leyendas nórdicas, relatos orientales o ideas fantásticas para encontrar un símil que fusionara ideas de femineidad con espíritu heroico. Así también en la cultura pop y de mass media actual el lugar conquistado en los últimos años es, para el proceso histórico, un verdadero salto social.

Es notorio que las ideas de la madre-diosa de las culturas originarias pre-hispánicas, las creencias con panteones de diosas femeninas como en Egipto (con sus propias sacerdotisas) o Sumeria y la India, las narraciones sobre espíritus femeninos de la naturaleza de amplias zonas de África y tantas otras haya sido dejado de lado en favor de las creencias dominantes de Occidente.

En general y, como parte de la asociación entre deseo, sexualidad y pecado, las representaciones iconográficas de muchas culturas presentan a mujeres que son a la vez una fuerza atrayente y por lo tanto fuertemente sexualizada. Esto presenta la paradoja de que aquello que atrae mata, lo que en el cine se tradujo como la femme fatale. Lo cierto es que se puede observar que tanto la forma como el contenido están profundamente imbricados y los personajes que han triunfado en el mundo del cine como representantes femeninos son justamente de doble polaridad. Si el arquetipo masculino se caracteriza en muchas ocasiones por la voluntad de dominio y sumisión al poder personal, en los personajes femeninos se presenta muy arraigado en forma subyacente la función de generar deseo.

Odiseo naufraga con su barco y llega a una isla en donde es recibido por Calipso que era una hija del titán Atlas y había sido obligada a vivir allí luego de que de los dioses olímpicos (con Zeus a la cabeza) la castigaran. Calipso lo retiene allí por nueve años y lo atiende, 
le brinda comida, techo y lo enamora día a día. Le ofrece bebida y sexo como parte de una vida en apariencia perfecta. Odiseo, que estaba en proceso de volver a su propia tierra en donde lo esperaban su esposa Penélope y su hijo Telémaco se va perdiendo en los encantos de Calipso que hace todo lo posible por retenerlo. Aquí se puede ver otra forma de personaje negativo (la tentadora) que no lo es por elección ni está buscando la destrucción, sino que anhela ser amada como única y no tiene remordimientos en vulnerar la voluntad de Odiseo para que se quede con ella. Por otro lado Odiseo queda sutilmente disculpado puesto que en definitiva fue ella quien lo retuvo. La historia cuenta que finalmente la diosa Atenea intervino para que Zeus enviara a Hermes a anunciarle que ella debía soltarlo y finalmente así lo hizo. Esta historia muestra la fuerte carga erótica implícita en el relato, en la que una vez más, la mujer seduce para poseer.

Históricamente hablando, las características femeninas en los hombres y las masculinas en las mujeres han sido fuertemente reprimidas en y desde la sociedad. Los hombres de corta edad aprenden a mostrar solo la faceta viril y escasamente emocional de sí mismos. Nuestra sociedad enseña a las mujeres que deben quitar importancia a las cualidades masculinas. En la actualidad, los hombres se afanan por recuperar algunas de sus cualidades femeninas suprimidas: la sensibilidad, la intuición y la capacidad para sentir y expresar las emociones. Las mujeres suelen pasar su vida adulta intentando recuperar las energías masculinas que la sociedad ha desestimado, la asertividad y el poder, entre otras. (Vogler, 2005, p. 96)

En las historias en las que la mujer asume el rol de villana, puede ser esta o muy bella u horripilante y desagradable. Esto incluso no sorprende ni a las audiencias ni a los críticos de cine que toman por natural que el rol femenino sea constreñido a esta simplificación. Si por el contrario en el abanico de villanos masculinos se encuentran personajes encantadores también los hay abyectos, pero allí no termina pues éstos pueden ser como quieran, jóvenes o viejos, atractivos o repelentes, tener máscara, ser etéreos o llevar casco como Darth Vader. Parecer sabios como Don Vito Corleone o crueles como Voldemort. No importa en absoluto que sea lindo o feo, que tenga un cuerpo exuberante o sea delgado, el asunto es su poder.

Esto no sucede con los roles femeninos ni en el mundo de las heroínas ni en el de las villanas. Si no es atractiva, bella y sensual tiene que ser pues una ogra espantosa, una bruja malformada o una monstruosidad aberrante. Es interesante señalar que está de tal manera normalizado que casi no existen roles en la pantalla para rostros y cuerpos que se podrían denominar comunes.

La bruja es pues la representación de todo aquello que las personas no quieren ser ni tener cerca. La tentadora en cambio es mirada como objeto de deseo y aunque sea una villana cruel, injusta y sanguinaria tendrá su encanto por el hecho de representar un ideal psicosocial instalado desde el fondo del inconsciente y por la continua repetición acerca de cuál es y debe ser el rol de la mujer y que éste, se base en su apariencia. Se puede ver como ejemplo Bellatrix LeStrange (Harry Potter, 1997, Cris Columbus), Jadis (Las Cróni- 
cas de Narnia, 2005, Andrew Adamson), Mystique (X-Men 2000, Bryan Singer), Harley Quinn (Escuadrón Suicida, 2016, David Ayer), La Reina (Blancanieves y la leyenda del cazador, 2012 Rupert Sanders), Hiedra Venenosa (Batman y Robin, 1997, Joel Schumacher), Phoenix (X-Men, 2000, Bryan Singer) o T-X (Terminator 3, 2003 Jonathan Moslow), Caterine Tramell (Bajos Instintos, 1992, Paul Verhoeven), todas ellas atractivas y adscriptas al rol de las tentadoras.

Por otro lado, y como contrapartida se puede ver Annie Wilkes (Misery,1987, RobRiener), Winifred Sanderson (El retorno de las Brujas, 1994 Kenny Ortega), Úrsula (La Sirenita, 1989, Ron Clements) o Dolores Umbridge (Harry Potter, 1997, Cris Columbus).

Estos contrastes permiten observar que la distancia entre unas y otras está dada no solo por la composición de personajes en su función narrativa sino por sus atributos físicos, su vestimenta y en especial por la imagen que proyectan desde el habla y el lenguaje corporal en el sentido de no deseables. La bruja tiene que ser fea, tener rasgos desarmónicos y presentar defectos corporales, pero además tiene que vestir mal. Es decir que no solo invoca la genética como elemento diferenciador sino una falta de culturización en el aspecto social representado por la vestimenta. Si una mujer tiene una falla corporal ésta deber ser escondida, tapada o camuflada, pues el varón no se complace en su mirada.

En las sagas nuevas de La Guerra de las Galaxias (2015, J.J. Abrams) su nueva protagonista es una mujer y representa de alguna manera ese poder femenino basado en la fuerza interior, la intuición y la perspicacia mucho más que en los atributos físicos o el pensamiento romántico. Rey es una joven que trabaja de recolectora de chatarra. Luego de más de tres décadas y de un mundo en constante cambio, la protagonista de la saga es una mujer. De una forma misteriosa y con el barro necesario que le da su oficio de chatarrera, saca a la luz un inmenso poder y no del tipo agresivo que oficia de belicosidad y deseo de poder sino de un espacio mucho más real que se sustenta en un intangible de gran valor: la determinación y el desparpajo de utilizar, sin experiencia, un sagrado sable láser.

$\mathrm{Y}$ ante todo este intento de sometimiento y creencia de superioridad se plantea el interrogante central que al hombre, en el fondo, estremece: ¿Envidia el hombre el poder concebidor de la mujer? Pareciera que la historia del arte mostrara un intento entre salvaje y sublime de dar vida. Las obras de arte cuando han sido dadas a luz embelesan con algún atributo que es esencialmente un rasgo de la vida. Es indudable que la capacidad de la mujer de engendrar un ser viviente supera como posibilidad a cualquier imitación por más buena que sea: la mujer crea vida. Y la mujer sangra. Ambos sucesos están íntimamente relacionados pues del mismo lugar que emana la sangre nacen las criaturas. El hombre busca poseer cuanto se encuentre por delante, sea esto para procrear o matar pues en el inconsciente parece no suponer gran diferencia. La pasión por las armas es igual al sexo y éste es igual a poder. Ser o creerse un prodigio sexual de potencia ilimitada tiene su equivalente en jugar a ser Dios con la vida ajena. Fabricar y disparar grandes balas o enviar misiles (obsérvese su forma fálica) a destruir ciudades o lo que fuera que se encuentre en el camino es para la representación del poder máximo, el de la vida y la muerte. De la misma manera que la mujer menstrua y con ello libera las células muertas de su interior o da vida y nutre hasta con sus propios pechos. La manera de resolver conflictos en el mundo masculino termina fatalmente en el surgimiento de la guerra. Las tierras en donde se desarrollan los 
combates se las ha denominado desde hace siglos "Campo de Marte". El planeta rojo, es también simbólicamente la esencia de lo masculino. Incluso su símbolo es un círculo con una flecha, un pene erecto, una espada.

En la serie Juego de Tronos (HBO), Daenerys Targaryen, conocida como Khalessi, ha propulsado un fenómeno de mujeres poderosas que ejercen el poder. Durante los años que la serie está al aire la cantidad de niñas a las que las madres han bautizado Khalessi o Daenerys demuestran lo pregnante del personaje. Llega al poder luego de comerse el corazón crudo de un caballo, salir indemne de una pira de fuego, perder a toda su familia, ser esclava, hacer nacer y criar tres dragones y liberar pueblos esclavos para terminar como "madre" de los necesitados. Una heroína de corte fantástico que cabalga dragones en el papel de libertadora social, curiosamente cerca de Evita, Juana Azurduy o Juana de Arco. En la sexta temporada está cautiva de una tribu de salvajes llamada dothraki. Es la viuda de un "Khal", un líder. Sin embargo, al ser ella extranjera (notoria referencia en un momento histórico en donde la inmigración es un tema de alarma mundial), ellos pueden decidir su destino. Se había casado con Khal Drogo quien verdaderamente y a su modo instintivo, la amaba. Ahora sin embargo su poder ha quedado reducido a nada según las leyes patriarcales. Así, los Khal están reunidos en una cabaña de madera. Las opciones que les presentan son dejarla encerrada para siempre en una casa con las otras viudas sin libertad ni poder, matarla, o usarla como esclava. Khalessi ingresa en el recinto, orgullosa, radiante y con estilo. Los hombres la denigran y hasta le dicen que la poseerán sexualmente hasta agotarla para que finalmente la usen hasta los caballos. Khalessi no se inmuta y les dice que ellos deben servirla. Ríen y bromean enardecidos y la amenazan. En ese instante ella suelta todo su poder.

Khalessi: - Son pequeños hombres. Ninguno está preparado para liderar a los Dothraki. Pero yo sí. Y lo haré

Khal: - ¿Servir a ella? ¿A una mujer?

Khalessi: - Oh no pequeños khals, ustedes no van a servirme. Ustedes van a morir."

Con sus manos sostiene los cuencos ardientes de fuego en la cabaña y los arroja sobre ellos. El fuego se propaga, y uno a uno, mueren entre el terror y el desconcierto. Khalessi permanece inmutable. Ella sale sin una sola herida. Su mirada es de una altiva paz y los jinetes se arrodillan frente a ella. Ha renacido de cautiva a líder de cien mil personas. En la historia, el poder femenino está presente en su relación con los elementos de la Naturaleza. Aquí es el fuego que como fuerza natural lo arrasa todo. El poderío aparente de los hombres por imposición de la brutalidad del cuerpo queda reducido literalmente a cenizas. Otro personaje de la serie es la adolescente Arya Stark que es la menos afortunada en belleza y gracia de todos los Stark (la familia heredera del trono del Norte) pero tiene una inteligencia e intrepidez que junto a su implacable carácter la han convertido en uno de los personajes favoritos. Aquí es notorio el grado de pregnancia del personaje si se tiene en cuenta que no representa casi ningunos de los atributos que se han reservado históricamente a las mujeres, incluso las guerreras. Su aspecto no deslumbra por su belleza ni por una pose pretendidamente sexy, se ufana de ello y además se presenta con otra nota 
curiosa y es que no desea alcanzar ningún poder, al contrario, lo que desea es la absoluta libertad. Quizás por ello es que ha establecido un lazo muy fuerte con adolescentes (ella lo es) y con la audiencia del programa: nadie quiera que muera. Y reafirmando su condición independiente, audaz y repleta de autoconfianza, destruye al Rey de la Noche, a quien se creía casi inmortal. No es solo un recurso dramático para de la dramaturgia sino la confirmación de un proceso, de una búsqueda, de un resultado inexorable: la aparición de una nueva ventana de posibilidades en el universo de las heroínas. Justamente, la que no responde a los patrones establecidos, la que decide, se escinde, varía, se multiplica y por último se decide, actúa y resuelve sin buscar a cambio ni honores, ni reconocimientos y mucho menos las adulaciones que buscarían los héroes. Hizo lo que tenía que hacer y lo hizo porque podía. He aquí un manifiesto contundente, la estructura piramidal y de poderío masculino se ve interrumpido por la acción inesperada de una adolescente que actúa desde lo inesperado, con un cuchillo, en la noche larga de la desesperanza. Así es que la versión más temida del mal encarnada en un poderío de potencia patriarcal, dominante y personalista se ve diezmada por un poder femenino en uno de sus estados de plena ebullición, entre la fuerza dinámica de su intención y el coraje definido por su auto valoración. Con toda su carga pop y a pesar de ser un entretenimiento para adolescentes, la saga de Los Juegos del Hambre (2012, Gary Ross) con su personaje central Katniss Everdeen posee cualidades que exceden sus atributos físicos y el simple relato de aventuras. Aquí se trata de una joven que es una arquera consumada y se ve envuelta en una saga de historias de supervivencia en una sociedad distópica en la que sobrevivir para las clases bajas es un lujo. Katniss no solo se revela como formidable guerrera y estratega natural, sino que aporta el elemento sensible y compasivo a la historia. Ese elemento difiere de la brutalidad y falta de consideración del impulso masculino sin refrenos y constituye una nueva esperanza en un mundo al borde del colapso. Sus armas son el arco y flecha lo cual ya es un rasgo asociado reiteradamente a guerreras desde tiempos remotos. De hecho, la compasión, la capacidad de trabajar en equipo y en especial su natural cualidad de líder la colocan dentro del universo de las heroínas. Cuanto más heroínas complejas, multifacéticas y plurales vayan naciendo así también sucederá con las villanas. Una y otra están conectadas no solo por la necesidad dramática sino por potenciación de los discursos que lleven a una nueva conceptualización de los roles de la mujer.

Se cuenta que los mongoles en su época de esplendor y en la que dominaron casi todo el mundo conocido tenían entre sus filas algunas guerreras notables. La más conocida fue la princesa Kuthulun. Se hizo conocida por la crónica de Marco Polo. Kuthulun fue hija de Kaidu, sobrina del Kublai Khan, descendiente de Genghis Khan máximo líder de las hordas mongolas. Desde chica había mostrado una especial habilidad para la lucha cuerpo a cuerpo y según se dice jamás había sido vencida por ningún hombre. Eliminó a los enemigos de su padre uno a uno. Debido a que en las luchas el que ganaba se quedaba con los caballos del vencido, había acumulado una gran cantidad. Tal fue su poder y capacidad de liderazgo que en un momento se le ofreció el título de Khan cosa que ella rechazó aduciendo que prefería estar al mando de las tropas. Era una gran tiradora con arco y una estratega implacable. Bajo su mando la horda de oro de los mongoles se expandió por Asia y Europa. Las guerreras mongoles cauterizaban uno de sus pechos para no entorpecer el arco que llevaban cruzado al cuerpo el cual usaban a todo galope disparando flechas. Así es que el 
arco y flecha se vincula a las armas preferidas de las guerreras desde hace mucho tiempo. Es natural puesto que si bien es una punta que se lanza no posee las características fálicas evidentes de la espada o la lanza y por otro lado requiere una mirada fría, concentrada y elíptica en la que se ha de calcular la distancia, el peso, la velocidad, inclinación y el viento lo cual requiere una gran capacidad de manejar datos en simultáneo. Al parecer Kuthulun había dicho que no desposaría a ningún hombre hasta que alguno la venza en el combate cuerpo a cuerpo. Así de firme era y con todo cuenta la historia que finalmente se casó con un hombre que no la desafió. Lo significativo reside entre otras cosas en que esto data del año 1206. La tradición de las mujeres arqueras continúa en Mongolia hasta el día de hoy. Hay muchos factores que convergen para esta nueva era de heroínas, desde las cuestiones sobre la igualdad de género, el mercado agrandado que representa a la industria del cine, la televisión, el comic y el entretenimiento en general el sumar consumidoras femeninas, la avidez por ver figuras femeninas en acción y atrevidas. Sin embargo, detrás de las capas más superficiales comienzan a emerger las fuerzas de la energía femenina con todo su resplandor. Si observamos la presencia de la mujer en las distintas pantallas y aún en libros o comics, veremos que en general y al arrancar el siglo se trataban de damiselas en apuros que serían luego rescatadas por heroicos varones. Pueden tratarse de superhéroes enmascarados como Daredevil, extraterrestres como Súperman, mutantes como Wolverine o simples mortales envueltos en situaciones de aventura y amor. En los comics primero y en las películas y televisión más tarde, comenzaron a incursionar mujeres que ejercían alguna clase de poder.

Durante la Segunda Guerra Mundial las editoriales de cómics de EEUU se vieron en aprietos porque los varones habían ido a la guerra y no había dibujantes ni guionistas $\mathrm{y}$-contra sus propios prejuicios- comenzarona contratar mujeres para el trabajo. Muchas acudieron y no solo se convirtieron en quienes impulsaron la industria durante esa época, sino que crearon nuevos personajes. Patrullas femeninas, heroínas de guerra que combatían nazis y demás personajes que llenaron las revistas de un nuevo brío. Varios nombres importantes salieron de ese momento. Algunas trascendieron tanto por sus personajes como por su propia labor artística. Los personajes femeninos dibujados por mujeres, tenían formas bellas y sexys, pero nunca eran representadas como lo hacían los hombres. La sensibilidad y el conocimiento del género hicieron que además de atractivas fuesen elegantes y cultas. Los diálogos y los dibujos revelaban una mirada claramente distinta que las que profesaban los hombres para los cuales solo debían ser unos cuerpos formidables con apenas algo de ropa. Las mujeres dibujantes (y los personajes que creaban) fueron un rayo de luz en una industria hasta entonces dominada por hombres. Algunos de esos personajes perduraron y otros simplemente desaparecieron y quedaron en el olvido. La sociedad americana (y mundial) necesitó que las mujeres volvieran a sus hogares a criar hijos y la maquinaria perversa de la sociedad machista continuó su andar sobre las ruedas de hierro del pensamiento masculino.

De los personajes femeninos sin embargo algunos perduraron tanto en el cómic como en la televisión. Del dibujo saltó a la televisión Wonder Woman (La Mujer Maravilla) con la bella y carismática actriz Linda Carter y fue todo un suceso durante años, e impuso una forma de poder femenino al servicio de la justicia. Venía el personaje de una historieta de la DC Comics y su traslado a la pantalla chica fue una apuesta arriesgada que rindió sus 
frutos. Wonder Woman es una amazona, hija de la reina Hipólita y vivía en la isla Temiscira. Para llegar allí había que traspasar un portal dimensional ya que ningún humano (menos aún un hombre) debía conocer el secreto de su existencia. Tenía un avión invisible y vestía un para la época atrevidísimo atuendo de pantalones cortos tipo malla y un top con pronunciado escote. Sin duda la elección de la actriz estuvo influida por los varones que manejaban los estudios en su totalidad en la década del sesenta. Un lazo dorado que usaba tanto para atrapar como para que los malvados confesaran lo que ella quisiera ya que no podían negarse a ello. Su fuerza era impresionante y podía correr a velocidades impensables. Pues bien, ella encarnó a la mujer perfecta, bella, inteligente, justiciera y noble, tenía los rasgos que hacían falta para que la serie fuese todo un éxito. Es extraño el caso de La Mujer Maravilla que siendo un éxito fenomenal en la serie televisiva de los ochenta haya tenido que esperar 35 años para tener su propia película.

"Yo quería salvar el mundo. Poner fin a la guerra y ofrecer la paz a la humanidad. Pero luego vislumbré la oscuridad que vive dentro de esa luz... Y aprendí que, dentro de cada ser humano, siempre habrá ambas cosas. Y cada uno debe elegir entre una y otra. Es algo que ningún héroe podrá vencer jamás. Ahora sé que sólo el amor puede salvar en serio al mundo. Entonces me quedo, lucho y me entrego por el mundo que considero posible. Ahora, ésta es mi misión. Para siempre." (Mujer Maravilla, 2017, Patty Jenkins)

Pero más allá del evidente mercantilismo oportunista que como producto detentaba, fue una punta de lanza para probar una tipología de heroínas mujeres. Solo el machismo instalado en el mundo hizo que no se hicieran inmediatamente muchas series similares más con la cantidad de heroínas que ya tenían patentados tanto la DC Comics como la Marvel. En el terreno de los dibujos animados, la aparición de Valiente de Pixar (2012, Mark Andrews - Brenda Chapman) con una particularísima historia donde la protagonista es una niña, nos muestra que este arquetipo ha llegado para quedarse. Su protagonista es Mérida, una niña de rizos colorados que no quiere -y no lo hace- adaptarse al rol pasivo que se espera de ella. Al contrario, se hace hábil en el uso del arco y flecha. Es contestadora y revela un carácter fuerte y decidido. Mérida es criada como toda niña para casarse y eso esperan sus padres y la sociedad toda. En la historia suceden varias cosas de índole mágica. Mérida se pierde en el bosque siguiendo unas luces brillantes de fuegos fatuos y llega donde la casa de una bruja a la cual pide un hechizo para "transformar" a su madre, ésta así lo hace y la convierte en una osa gigante. Al comienzo parece un hecho casi divertido incluso tierno pero su "madre-osa" de a poco comienza a perder su memoria humana y se asimila a su nuevo mundo animal (es decir instintivo). Mientras tanto un enemigo temible llamado Mor'du (también oso) aparece para complicar las cosas. Este mismo oso ha sido quien en una lucha con su padre le ha hecho perder una pierna y ahora pone en riesgo a toda la población. Nos enteramos entonces que el oso había sido un bravo guerrero sediento de poder y que había hecho el mismo hechizo que Mérida con su madre. Ahora la situación es dramática pues el pueblo (y el rey padre) confunden el oso enemigo con la nueva osa que es en verdad su mujer y madre de la princesa y quieren matarla lo cual casi logran. La bruja había dejado sin embargo la fórmula para deshacer el hechizo. Le dice que "remiende 
el vínculo que el orgullo rompió" y luego de pensarlo descubre que debe arreglar el tapiz roto en su furia. La historia concluye en que la madre se reconvierte en humana, el malvado Mor'du es derrotado y todos aprenden una lección.

En el Señor de los Anillos su protagonista, Frodo el hobbit llega junto a la bellísima y poderosa Galadriel, quien gobierna el bosque. Ella le ofrece mirar por el espejo de agua mágico para ver el futuro. Horrorizado por lo que ve aparta la vista. Ella también lo ha visto: el fin de la Compañía del Anillo y un nuevo terror. Frodo sobrecogido por lo inmenso de su misión le ofrece el Anillo Único a la Reina de los Elfos.

Galadriel: - ¿Me lo ofreces sin reservas? No dudaré que mi corazón lo ha deseado fervientemente.

[De repente, se muestra poderosa y malvada] ¡En el sitio del Señor Oscuro instalarás una reina! ¡No oscura pero hermosa y terrible como el alba!¡Traicionera como el mar! ¡Más fuerte que los cimientos de la Tierra! ¡Todos me amarán, desesperados!

[Se da cuenta de lo que acaba de hacer y de decir]

He superado la prueba. Me someteré. Partiré al Oeste, y seré siempre Galadriel.

El universo ficcional de la narrativa audiovisual se completará con la presencia de la energía femenina y es posible que, si de alguna manera logra la sociedad aceptar el cambio y profundizando su contenido, nos complete y devuelva el equilibrio perdido. Un orgasmo gritado y liberador de energía era suficiente para poner en pánico al hombre, tan afianzado a la tibieza del razonamiento. La castración de la sexualidad y goce femenino no fue otra cosa que miedo. El vacío que se generaba le producía al hombre un desconcierto tal que prefirió golpear con dureza los impulsos de la mujer. Ahora, este impulso se ha liberado y tomado las formas de la creación. El hombre ha tenido y le tiene miedo a la mujer (aunque nunca lo confiese abiertamente). Por más que se erija en dueño y amo de la familia e intente parecer quien manda, el hombre íntimamente sabe que su destino depende de la voluntad y deseo de la mujer. Todo hombre ha sido parido por mujer y antes de eso fue llevado por nueves meses, nueve lunas en el útero, alimentado y simbióticamente unido a la madre. No hay forma que en la memoria interna no quede el acto reflejo de comprender que todo en la vida dependía de ella. Y por lo tanto y por simple proyección, todo en su vida adulta depende de una mujer. Pero la mujer no se muestra ni comporta como los hombres entienden que ellas deberían hacerlo. Fuera de los arquetipos de la mujer manejadora y cruel de tantas telenovelas en donde éstas se enfrentan a las simples y pobres empleadas que con su candor hechizan al hombre en pugna, aparecen mujeres que son en todo sentido dignas de ser imitadas que luchan, creen en sí mismas, en su causa, que no esperan a ser liberadas ni salvadas y mucho menos perdonadas. Mujeres que construyen su destino y se atan a él. El personaje Sarah Connor de Terminator (James Cameron, 1984), es un ejemplo de una mujer que lucha hasta lo improbable. Posiblemente uno de los personajes más icónicos del cine en cuanto a determinación contra toda chance.No solo porque su rol dentro de la historia es central sino porque ha aportado al universo de heroínas femeninas del cine un aspecto no muy común por los años ochenta. Y en contraposición con los caracteres masculinos clásicos hay una visión por la vida a largo plazo que emite aquella clase de idea 
y visión que hacen que el vacío quede aislado. Si la energía del Terminator -como máquina masculina indestructible- es una fuerza ciega de la ingeniería humana que ha tomado control sobre nosotros, Sarah Connor representa no solo la esperanza sino la voluntad de lucha y trascendencia. Si para que una heroína surja y se expanda por sobre el imaginario del poder patriarcal y endurecido es necesario la transfiguración de la imagen de la damisela en apuros en una mujer que bien se arregla por sí misma, también es cierto que ella puede como nadie vislumbrar la importancia última de la vida.

"Sarah Connor: - John, fue una estupidez ir a buscarme. ¡Maldita sea, tienes que ser más listo! Ha faltado poco para que te maten. ¿En qué estabas pensando? No debes arriesgarte por nadie, ni siquiera por mí ¿lo entiendes? Eres demasiado importante. ¿Lo comprendes?

John Connor: - Tenía que sacarte de ese horrible lugar. Lo siento...

Sarah Connor: - No necesitaba tu ayuda, sé cuidar de mí misma. El futuro desconocido rueda hacia nosotros. Por primera vez lo afronto con un sentimiento de esperanza porque si una máquina, un Terminator, puede aprender el valor de la vida humana, tal vez nosotros también podamos."

La teniente Ripley, adversaria del Alien resiste sola mientras que la criatura deshace uno por uno de los tripulantes del Nostromo, en donde ya no primará la fuerza (que es sin dudas desproporcionada respecto de la criatura Alien) sino la fortaleza, la sagacidad y la constancia. Y es justamente aquí donde lo femenino prima desde la biología a la psiquis y del ánimo a lo concreto: para vivir es menester sobrevivir y para ello es conveniente pensar y hacer, curar y prevenir, observar y metamorfosearse con la realidad en un camuflaje constante como lo hacen tantas especies animales, plantas y la naturaleza toda.

Lara Croft presenta un caso excepcional. Aparece como protagonista del videojuego Tomb Raider de 1986. Y si bien han existido otras heroínas y guerreras en la industria del video juego (como la emblemática Chun Li de Street Fighter), Lara es la primera protagonista mujer. Curioso caso de un personaje femenino audaz, atrevido e independiente al que jugaban tanto mujeres como hombres. Trinity es la heroína interna de Matrix, la matriz en la cual se funde Neo quien protagoniza la saga; es ella quien lo hace portador del poder. Una guerrera que ama tan profundamente que rompe todas las reglas para salvarlo y lo logra. Son muchas las heroínas que conforman elpodio de mujeres del mundo de la ficción que metaforizan la acción cotidiana de millones de otras que pertenecen al mundo real. En diversas leyendas antiguas se habla de historias de mujeres despechadas, reinas, diosas o brujas que han sido engañadas y utilizadas por los hombres y desde su resentimiento se han convertido en seres destructivos. Pues bien, aquí hay un elemento disruptivo de la lógica lineal de las historias ya que éstas se revelan como inicialmente frágiles y crédulas para luego convertirse en hembras sanguinarias y crueles. Antes de esto hubo una mentira fundacional que invirtió lo dador de vida por aquello que la quita. Es Lilith que devora o Kali, que representa las fuerzas tenebrosas de la naturaleza. El corazón ardiente herido expresa su desesperación a través de un clamor que no puede ser oído y desde los subterráneos del alma implora y ejecuta una venganza que ni redime ni cura. En el estado de agitación exacerbada y con el dolor a cuestas se revuelve en su propia capacidad de ahor- 
car y destripar el corazón y el ánimo de los hombres para luego devorarlos. La mencionada Daenerys cae en la última temporada de Juego de Tronos (capítulo 5) en el estereotipo de la "despechada" y en medio del dolor y la rabia, quema una ciudad entera y a sus inocentes civiles montada sobre su dragón. Cabe preguntarse si los guionistas buscaron conformar un prejuicio, mantener un paradigma, satisfacer una creencia o simplemente Deus ex Machina y la mujer enojada arrasa con todo. Beatrix Kiddo jura vengarse de Bill y le llevará una indecible cantidad de sufrimiento llegar a él ya no solo para matarlo como dice el título Kill Bill (Quentin Tarantino, 2003-2004), sino para ver al padre de su hija, el amor de su vida, su admirado guerrero sin amo y decidir contra toda chance que lo ha de liquidar. Y lo hace. Esta fuerza radica en el conocimiento de sí misma y la sublimación de las pasiones. Las pruebas del personaje arquetípico masculino han sido aquellas que implican la valentía, el coraje, la búsqueda de la verdad, el amansamiento del temperamento y los instintos, la humildad y la justicia, pues son todos estos atributos que, aunque idealizados, suelen escasear. Y en esa transmutación es que radica el poder a conquistar, y la posibilidad de convertirse en un héroe de nivel superior.

Para las heroínas del futuro será igualmente un arduo trabajo, el de la conquista de sus pasiones que la someten y de todas aquellas falencias del carácter que no le permiten surgir en su máximo potencial. Será un amanecer de la consciencia para una nueva igualdad en donde las heroínas tendrán un poder inconmensurable más allá de lo evidente. La auto observación serena y el autodominio de su mundo emocional, el manejo de las energías de la naturaleza, la fuerza del corazón y las de las entrañas de la vida, la maternización vital de universos enteros, y tantos otros aún por descubrir y cimentar.

De ese humus existencial y terrenal, emergerá una fuerza desconocida, nueva y refrescante que hará de néctar para la consubstanciación de las nuevas heroínas del siglo XXI.

\section{Lista de referencias bibliográficas}

Segato, R. (2016). La guerra contra las mujeres, Ed. Traficantes de Sueños

Tolkien J.R.R. (1954). El señor de los anillos, Allen \&Unwin,

Vogler, C. (2005). El Viaje del Escritor. Madrid: Robin Book. (pp. 54, 64, 89, 96)

\section{Bibliografía}

Lieberman, Al. (2006). La Revolución del Marketing del Entretenimiento (UP) Aristóteles, (siglo IV AC.) Poética

Bordwell, D. (1985). La narración en el cine de ficción. Editorial Paidós. Barcelona, España

Campbell, J. (1959). El héroe de las mil caras, psicoanálisis del mito. Fondo de cultura económica, México (pp. 55, 62, 90, 99, 107)

Campbell J. (1991). El poder del mito, Emecé, Barcelona (pp. 38)

Campbell, J. (1980). Los mitos en el tiempo. Emecé Editores. Buenos Aires, Argentina

Eco, U. (1974). La Estructura Ausente, Editorial Lumen. Barcelona, España

Frazer, G. (1944). La Rama Dorada. Editorial Fondo de Cultura Económica. Santa Fe de Bogotá, Colombia 
García Márquez, G. (1995). Como se escribe un cuento. Editorial Voluntad, Santa Fe de Bogotá.

Graves, R. (2007). Los mitos griegos. Alianza Editorial. Buenos Aires, Argentina

Heindel, M (1932). Misterios de las grandes óperas. Editorial. Kier, Buenos Aires, Argentina. Jung, C.G. (1993). Encuentro con la Sombra (compilación) Editorial Kairós, Buenos Aires, Argentina

Jung, C.G (1976). Psicología y Religión. Editorial Paidós. Barcelona, España

Jung, C.G. (1964). El hombre y sus símbolos. Editorial Paidós, Barcelona, España

Jung, C.G. (1951). AION Contribución a los simbolismos del sí mismo. Paidós, Buenos Aires, Argentina

Maitena (2006). Mujeres Alteradas. Sudamericana Lumen

May, R. (1993). Encuentro con la Sombra, Editorial Kairós, Buenos Aires, Argentina

McKee, R. (1997). Story, el guión. Editorial Alba. Barcelona, España

Niedner, H. (1986). Mitología Nórdica. Editorial Edicomunicación. Barcelona, España

Quino (2001). Toda Mafalda. Ediciones de la Flor

Salas Sommer, D. (1998). Moral para el Siglo XXI, Fundación Instituto Filosófico Hermético, Buenos Aires, Argentina

Segato, R. (2018). Contra-Pedagogías de la crueldad, Prometeo Libros, Buenos Aires, Argentina

Segato, R. (2016). La guerra contra las mujeres, Ed. Traficantes de Sueños

Seger, L (1987). Como convertir un buen guión en un guión excelente. Editorial Rialp, Buenos Aires, Argentina

Velayos, T. (1995). George Lucas el poder de la fuerza. Editorial Royal Books, Barcelona, España

Vogler C. (2005). El viaje del escritor. Madrid: Robin Book.

\begin{abstract}
In the narrative territory, the fable has been established from a male conception since the foundational times of culture. Nevertheless, strong female characters (heroines) have existed from Aristófanes (Lysistrata) to the present day; Joan of Arc, the Celtic Queen Boudicca, Juana Azurduy (Argentine historical character); Mérida from "Brave", Katniss Everdeen in The Hunger Games, Khalessi in Game of Thrones; female Captain Marvel, Wonder Woman; Beatrix Kiddo from Kill Bill, Trinity in Matrix, Rey the scavenger in Star Wars (who incarnates "The Force" and stands up to the Empire). Hundreds of examples exist where we can find a structural, aesthetic and ethical change which refresh narratives and their fables.

Women have advanced noticeably in every field in these past years thanks to the struggle of feminist movements. As a consequence of the permanent quest in search of their social role, and the evident failure of the patriarchal system, cracks in the social structure are appearing. The transformation powered by the Women's movements traverse the core structure of our society, making itself evident in different aspects of culture, in its more ample definition. The emergence of a new female character -a restricted role model before now- challenges the existing archetypical structures and promises changes towards a new, wider, more inclusive and diverse narrative.
\end{abstract}


In the present day, empowered women's participation in all social strata is on the rise. This is true for the social, material world and is also observable in the cultural mirror through diverse artistic productions; narrative in film and television, literature, mass media and digital platforms.

A democratization process of information, aesthetic and argumentative criteria appears to inaugurate -at a slow but steady pace- a new figurative view of the world. One of the more present, recognizable and active forms is the audiovisual account in which new archetypes of heroic characters, with intrinsically feminine attributes conquer the stories, the audience and box office.

If for humanity storytelling has been founding of its own culture, the change in form, manner and point of view, -thus a transformation in the way we narrate- changes the historical conception and cosmovision of the world. The new fable shall not be the like the on before it, neither will it be like its opposite: it shall be a completely different conception, transversal, multidimensional, inclusive and creative.

This projects aims to breach dominant ways of thinking and generate a new map in the narrative territory towards the discovery of new worlds.

Key words: Heroine - woman - gender roles - narrative - archetype - paradigm - empowerment - feminine - map - territory.

Resumo: No território da narrativa, as histórias foram estabelecidas a partir de uma concepção de corte masculino desde os tempos fundacionales da cultura, no entanto têm existido desde os tempos de Aristófanes (A rebelião das mulheres), personagens como Juan de Arco, a rainha celta Boudicca, Juana Azurduy até Mérida de Brave (Valente), Katniss Everdeen nos Jogos da Fome, Khalessi de Jogo de Tronos, Capitã Marvel, a mesma Mulher Maravilha, Beatrix Kiddo de Kill Bill, Trinity em Matrix, Rei a chatarrera de Star Wars que encarna "a Força" e enfrenta ao império. Assim, existem centos de exemplos onde se observa uma mudança estrutural, estético e ético que contribui uma visão refrescante à narrativa. Nos últimos tempos observou-se um avanço extraordinário da mulher em todos os campos graças às lutas dos movimentos femininos. Como consequência de uma busca permanente das mulheres de seu papel social no mundo e em linha direta com o evidente fracasso do modelo patriarcal, pode ver-se um craqueamento nas estruturas sociais que cuja epiderme tem sido cuarteada pelos acontecimentos da história. Isto é, que o processo de transformação social impulsionado pelo feminino, atravessa a estrutura mesma de nossa sociedade, evidenciando-se nos diferentes aspectos da cultura em sua definição mais ampla.

O aparecimento de um novo tipo de personagem feminina -até agora vedado como modelo- põe em xeque as estruturas arquetípicas existentes e são uma promessa de mudança para uma nova narrativa mais ampla, inclusiva e diversa.

Hoje em dia pode observar-se uma crescente participação de mulheres empoderadas em todos os estratos da sociedade. Isto se dá tanto no âmbito do mundo real como em seu espelho cultural através das mais diversas produções artísticas e narrativas do cinema, a televisão, a literatura, os meios de comunicação e nas plataformas digitais.

Esta sorte de democratização da informação e dos critérios estéticos e argumentales inaugura de forma lenta mas segura, uma nova forma de visualização do mundo. Uma de 
suas formas mais ativas, reconocibles e presentes pode observar-se em no relato audiovisual em onde o aparecimento de novos arquetipos de mulheres heroicas, com valores intrinsecamente unidos ao feminino, arrasam, não só no discurso sina nas plateias e nas eleições do público.

Se para a humanidade o narrar histórias tem fundado sua própria cultura, a mudança de signo na maneira e forma em que se olha e portanto relata muda o sentido da história, e assim muda a cosmovisión do mundo. O novo relato já não será igual ao anterior nem seu oposto: será uma concepção totalmente diferente, transversal, multidimensional, integrador e criativo.

Este projeto propõe-se abrir uma brecha no pensamento dominante e gerar um novo mapa para a reflexão no território da narrativa, rumo à descoberta de novos mundos.

Palavras-chave: Heroína - mulher - gênero - narrativa - arquetípica - paradigma - empoderamento - feminino - mapa - território.

[Las traducciones de los abstracts fueron supervisadas por el autor de cada artículo] 